\title{
Electrical Stimulation of NIH-3T3 Cells with Platinum-PEDOT-Electrodes Integrated in a Bioreactor
}

\author{
Grit Blume $^{1}$, Wiebke Müller-Wichards ${ }^{2}$, Christiane Goepfert ${ }^{1}$, Ralf Pörtner ${ }^{1}$ and Jörg Müller* ${ }^{2}$ \\ ${ }^{1}$ Institute of Bioprocess and Biosystems Engineering, Hamburg University of Technology (TUHH), Germany \\ ${ }^{2}$ Institute of Micro System Technology, Hamburg University of Technology (TUHH), Germany
}

\begin{abstract}
The objective of this work involves the development and integration of electrodes for the electrical stimulation of cells within a bioreactor. Electrodes need to fit properties such as biocompatibility, large reversible charge transfer and high flexibility in view of their future application as implants on the tympanic membrane. Flexible thin-film platinumpoly(3,4-ethylene-dioxythiophene)-electrodes on a poly(ethylene terephthalate)-foil manufactured using microsystems technology were integrated into a bioreactor based on the design of a 24 well plate. The murine fibroblast cell line NIH3T3 was cultured on the foil electrodes and the cells were stimulated with direct voltage and unipolar pulsed voltage. The amplitude, the pulse length and the ratio of pulse to pause were varied. The stimulated cells were stained in order to determine the angle between the cell cleavage plane of the dividing cells and the vector of the electric field. These angles were subsequently used to calculate the polarization index, which is a measure of the orientation of the metaphase plane of dividing cells that occurs for example during wound healing or embryonic morphogenesis.
\end{abstract}

Keywords: Electrical stimulation, orientation of metaphase plate, cell culture, fibroblasts, integrated biocompatible electrodes, polarization index.

\section{INTRODUCTION}

Physiological electric fields occur for example during wound healing and embryogenesis [1, 2], where electric field induced orientation of the cell cleavage plane and directed migration of cells is required. The physiological electric field of the wound is the most important cue for successful wound healing whereas chemical signaling pathways only play a minor role [3].

Electrical stimulation of cells causes numerous effects. One of these is the polarization of the cell and the subsequent orientation of the metaphase plate during mitosis [4] on application of direct or unipolar current to the cells. Lipids, associated growth factor receptors and other moieties such as F-actin accumulate at the cathodal side of cells exposed to adequate electrical stimulation, and the cells become polarized. During mitosis, a centrosome or an aster microtubule can be entrapped by these molecules accumulated at one side of the cell, the mitotic spindle consequently be fixed and thus the orientation of the cell cleavage plane be determined [5]. Our objective was to provide a system for culturing and stimulating cells with physiological electric fields in a bioreactor and to design a protocol for the evaluation of the effects of electrical stimulation of cell cultures using thin film electrodes. Another point of interest was the evaluation of the electrodes themselves, especially the electrode materials,

*Address correspondence to this author at the Institute for Micro System Technology, Eissendorferstr. 42, D-21073 Hamburg, Germony;

Tel: +49 404287830 29; Fax: +49 404287823 96;

E-mail: j.mueller@tuhh.de regarding their compatibility and suitability for biological and medical applications.

\section{MATERIALS AND METHODS}

Electrode manufacture: The carrier material used for the flexible electrodes was a $13 \mu \mathrm{m}$ thick poly(ethylene terephthalate)-foil (PET-foil) from the company GoodFellow. This flexible carrier material is biocompatible [6] and prevents tissue damage because of its flexibility [7]. These properties of the carrier material were deemed to be important since the electrodes are to be used as implants for the stimulation and furthermore for the survey of wounds at the ear drum in future. Platinum and gold are used as electrode materials because of their good biocompatibility and corrosion resistance [8].

Gold and platinum electrodes were used in preliminary experiments regarding the orientation of the cell bodies. The specific electrical conductivity of platinum is quite low $(\kappa=$ $\left.10.2 \times 10^{6} \mathrm{~S} / \mathrm{m}\right)$ compared to that of gold $\left(\kappa=490{ }^{6} \mathrm{~S} / \mathrm{m}\right)$ [9]. Since the platinum electrodes showed a high resistivity (data not shown) due to their lower conductance, a sandwich structure with a gold and a covering platinum layer was used for the experiments regarding orientation of the cell cleavage planes. Platinum has a better biocompatibility than gold (due to lower corrosiveness), therefore it is used as top layer.

Here, the manufacturing of the gold-platinum-electrodes is detailed. At first, a $110 \mathrm{~nm}$ thick layer of titanium was sputter deposited on the PET-foil, acting as an adhesion promoter. Then a gold layer was sputtered on the titanium, followed by a platinum overlay. These metal layers were 
patterned during the sputtering process using a shadow mask. The shadow mask was processed by anisotropic etching of a silicon wafer. The platinum electrodes were coated with poly(3,4-ethylene-dioxythiophene) (PEDOT), which is an intrinsically conductive polymer (ICP). ICPs are organic polymers which conduct electricity by virtue of conjugated p-orbitals which form a one-dimensional electronic band, where the electrons can move. The conductivity of ICPs is in the range of that of semiconductors. PEDOT was chosen as a coating because of its excellent electrical properties like low impedance of the electrode-electrolyte-interface, a high charge injection capacity (CIC), and a high charge storage capacity [8]. PEDOT-coated electrodes do not exhibit the typical capacitive behavior of metal electrodes due to interface polarization (formation of a Helmholtz-layer) at lower frequencies [10]. The easy processing, the good thermal and chemical stability [8] and its excellent biocompatibility [11] were additional criteria for choosing PEDOT as a coating material. A PEDOT dispersion was spin-coated and subsequently tempered for polymerization. A $200 \mathrm{~nm}$ thick polymerized layer of conducting polymer was obtained. The PEDOT layer was structured by a lift-off-technique.

The electrodes used in the preliminary experiments were manufactured with the same techniques, but with only one metal layer (either gold or platinum) on the titanium layer, and a PEDOT-coating was not realized.
Evaluation of the electrodes, scanning electron microscopy (SEM): In order to detect possible corrosion or other alteration at the electrode surface caused by electrical stimulation, the electrodes were investigated with scanning electron microscopy before and after use.

Evaluation of the electrodes, energy dispersive $X$-ray (EDX): The electrodes were analyzed by dispersive X-ray during the SEM-session. A change in the elemental composition, e. g. due to corrosion or other alteration was rendered detectable as we performed energy dispersive X-ray analysis of the electrodes before and after cultivation and stimulation.

Cell culture: The murine fibroblast cell line NIH-3T3 was cultivated in Dulbecco's Modified Eagle Medium (DMEM) high glucose with 10\% FBS (fetal bovine serum), $100 \mathrm{U} / \mathrm{ml}$ penicillin and $100 \mu \mathrm{g} / \mathrm{ml}$ streptomycin. In order to facilitate the exposure of cells to electric fields, the design of the perfusion bioreactor introduced by Nagel-Heyer et al. [12] was modified. The bioreactor for electrical stimulation consisted of a transparent base plate and a 24 well equivalent top frame as seen in Fig. (1A).

Between these base and top parts of the bioreactor, the foil electrodes were clamped. Joint rings at each well bottom prevent leakage.

In all, 16 wells, with foil electrodes at their bottom, were used for cultivation (see Fig. 1B). NIH-3T3 cells were seed-

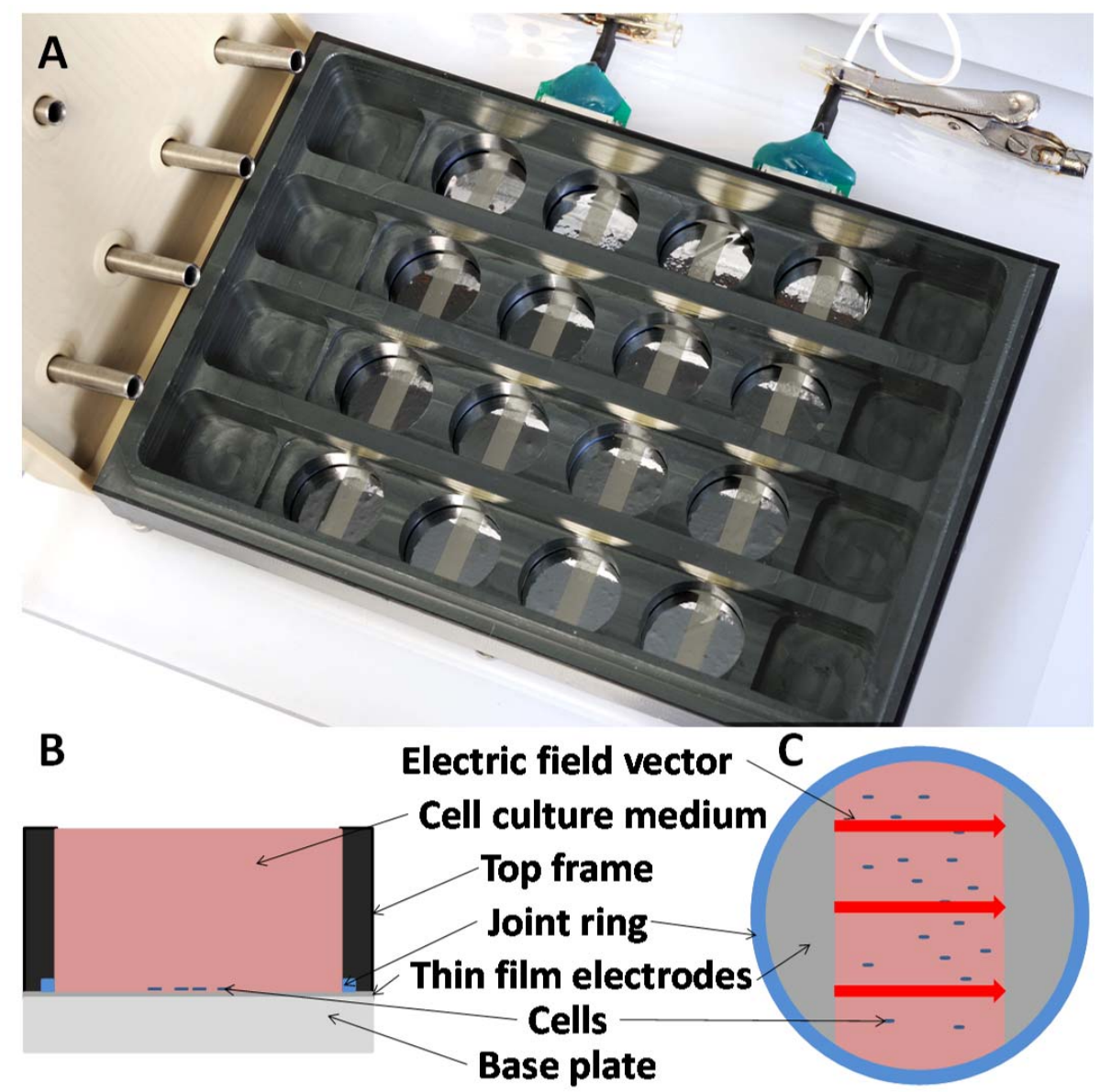

Fig. (1). A: Bioreactor with integrated electrodes, connected using flexible printed circuit connectors, for electrical stimulation of adherent cells, B: Cross section of one well, C: Top view of one well 
ed on the foil electrodes (see Fig. 1C) and the bioreactor was treated like a standard 24 well plate. The initial cell density was $2 \times 10^{4}$ cells per well.

A watertight box with the stimulation electronics was placed on the base plate next to the bioreactor and the electrodes were connected to the voltage source via flexible printed circuit connectors as can be seen in Fig. (1A).

The growth curve of these NIH-3T3 cells was determined before the stimulation experiments in order to find the adequate point in time for the onset of electrical stimulation. The cells had to be in the exponential growth phase during stimulation since mitosis was to be influenced.

EF exposure: The stimulation electronics provides both direct and unipolar pulsed voltage. The frequency could be varied between $16 \mathrm{~Hz}$ and $2 \mathrm{kHz}$, the voltage from 0 up to $600 \mathrm{mV}$ (peak to peak values) and stimulation pulse to pause ratios of 1:1, 1:10 and 1:100 could be chosen. In order to set the amplitude and frequency, an oscilloscope was connected to the stimulation box. After adjusting the stimulation regime, the oscilloscope was disconnected from the stimulation box and the electrodes were connected to the stimulation device.

Three days after seeding the cells in the flow chamber, the electrical stimulation was started. From this point in time until the end of the stimulation, the cell culture was in the exponential growth phase and hence many dividing cells could be stimulated. Before the onset of electrical stimulation, the cell culture medium was exchanged. Three rows of the bioreactor, each with four wells, were stimulated while one row served as a control.

Direct and unipolar pulsed voltages were used for cell stimulation. The duration of the stimulation was set to $20 \mathrm{~h}$, which corresponds to the doubling time of NIH-3T3 cells [13].

The amplitude of the voltage was varied between $250 \mathrm{mV}$ and $500 \mathrm{mV}$ during assays with direct voltage. During pulsed stimulation, the voltage was maintained at $600 \mathrm{mV}$ and the frequency of the unipolar pulsed voltage was varied between $16 \mathrm{~Hz}$ and $2 \mathrm{kHz}$ (corresponding to pulse durations of $30 \mathrm{~ms}$ and $0.25 \mathrm{~ms}$, respectively). During assays with ratios of

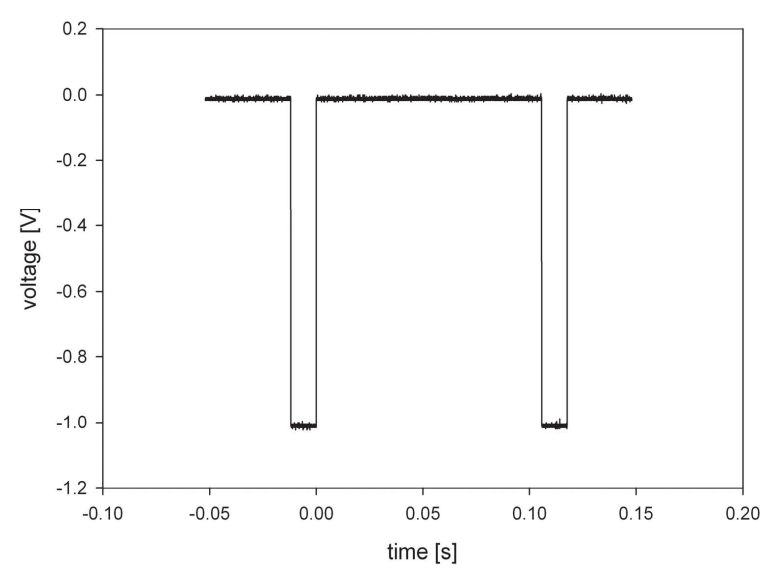

Fig. (2). Stimulation profile with pulse to pause ratio of 1:10 with 12 ms pulse duration. stimulation pulse to pause greater than $1: 1$, the voltage was kept constant at $600 \mathrm{mV}$, the puls length was set to $12 \mathrm{~ms}$ (see Fig. 2) and the ratios given above were applied.

After $20 \mathrm{~h}$, the electrical stimulation was ceased, the cell culture medium removed and the cells were fixed and stained.

\section{Confocal Microscopy}

To enable microscopic analysis, the tubulin of the cytoskeleton (and of the mitotic spindle) and the DNA were stained. First, the cell culture medium was replaced by $250 \mu$ l Histofix (phosphate buffered 4\% formaldehyde solution). After 20 min the cells were washed three times (once with 10 min residence time) with phosphate buffered saline (PBS). Subsequently, a blocking buffer containing $0.1 \%$ Triton X-100 was added and the cell culture was incubated for $60 \mathrm{~min}$ in order to augment the permeability of the cell membrane to the staining molecules. Then the buffer was removed, 50 to $80 \mu$ l anti- $\alpha$-tubulin solution was added and the samples were stored for $17 \mathrm{~h}$ at $4^{\circ} \mathrm{C}$ in the dark. Afterwards, the cells were washed with $250 \mu$ l PBS three times (once with 10 min residence time) and DNA staining was performed. The staining of the DNA was realized either with DAPI (4', 6-diamidino-2-phenylindole) or $\mathrm{H} \mathrm{33342,} \mathrm{which}$ are equivalent dyes for staining of DNA. The cells were incubated with $100 \mu \mathrm{l}$ DAPI-solution $(0.2 \mathrm{ml}$ DAPI stock solution with a concentration of $5 \mu \mathrm{g} / \mathrm{ml}$ suspended in $10 \mathrm{ml}$ methanol) for $15 \mathrm{~min}$ at $37^{\circ} \mathrm{C}$; the cells with the Hoechst stain $\mathrm{H} 33342\left(1 \mu \mathrm{g}_{\mathrm{H} 33342} / \mathrm{ml}_{\mathrm{PBS}}\right)$ were incubated for $45 \mathrm{~min}$. The DAPI or H 33342 staining solutions were removed and the cells were washed three times with PBS as described above in order to remove the excess of the staining solution. Thereafter the foil electrodes were removed from the bioreactor and were cut into pieces equivalent to one well. To improve the quality of imaging by microscopy, DAKO Fluorescent Mounting Medium was applied to the foil electrodes which were fixed between a microscopic slide and a cover slip. These samples were stored in the dark at a temperature between $4^{\circ} \mathrm{C}$ and $8^{\circ} \mathrm{C}$.

The anti- $\alpha$-tubulin staining solution contains a monoclonal anti-body conjugated with the fluorochrome FITC (fluorescein isothiocyanate). FITC has a green fluorescence $(590 \mathrm{~nm})$ when it is excited with blue light $(515 \mathrm{~nm})$ and

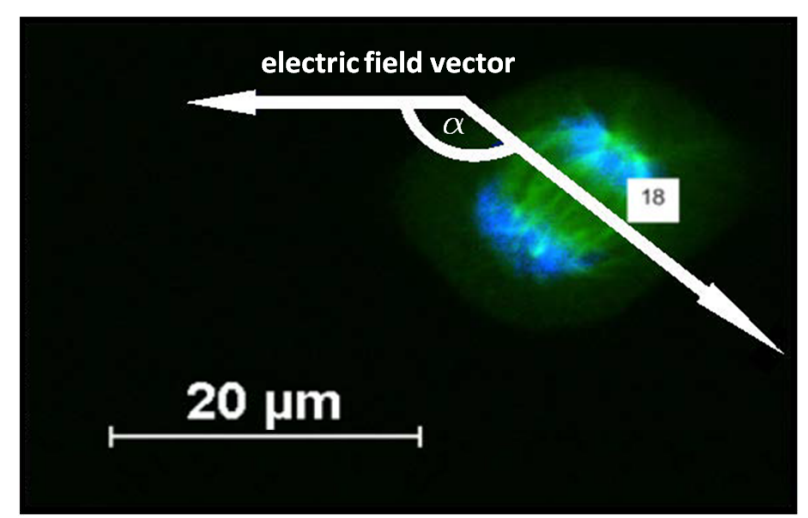

Fig. (3). Stained NIH-3T3 cell, with angle between electric field vector and cell cleavage plane. 
hence stained tubulin appears green. DAPI and $\mathrm{H} 33342$ have a blue fluorescence when they are excited with ultraviolet light (385 nm). The stained DNA appears blue and its emission maximum is at $461 \mathrm{~nm}$.

By means of fluorescence microscopy, the foil electrode samples were scanned looking for dividing cells. Then, pictures of the dividing cells were taken via confocal laser scanning. The pictures of the green emission of the tubulin and of the blue emission of the DNA were superimposed in order to determine the angle between the electric field vector and the cell cleavage plane.

With the aid of the NIS Elements software, the angles $\alpha$ were determined by the following method: the electric field vector was determined at first. Therefore the electrode edge was taken as a reference for the electric field vector which is vertical to the electrode edge. Then, a line was drawn between the MTOCs (microtubule organizing centers) in such a way that it is perpendicular to a line which would join the two MTOCs. The angles between the electric field vector and the line between the MTOCs were measured in every dividing cell using NIS Elements as shown in Fig. (3) and subsequently used for the calculation of the polarization index (PI). The PI was calculated for each well.

Orientation of cell bodies: In the preliminary tests, different electrode materials were evaluated and the orientation of cell bodies in the electric field was determined. Therefore NIH-3T3 cells were seeded on gold and platinum foil electrodes. The cells were stimulated with unipolar voltage with a frequency of $50 \mathrm{~Hz}$ at an amplitude of $500 \mathrm{mV}$. After stimulation, the cells were fixed and stained as described in 'confocal microscopy' and the angle between the longitudinal axis of the cell body and the electric field was measured with the NIS Elements software. The electric field vector was determined as describe before. Then, a line was drawn representing the longitudinal axis of the cell. The angle between the electric field vector and this axis was determined for a representative group of cells per well. ted.

These angles were subsumed in groups of $20^{\circ}$ and plot-

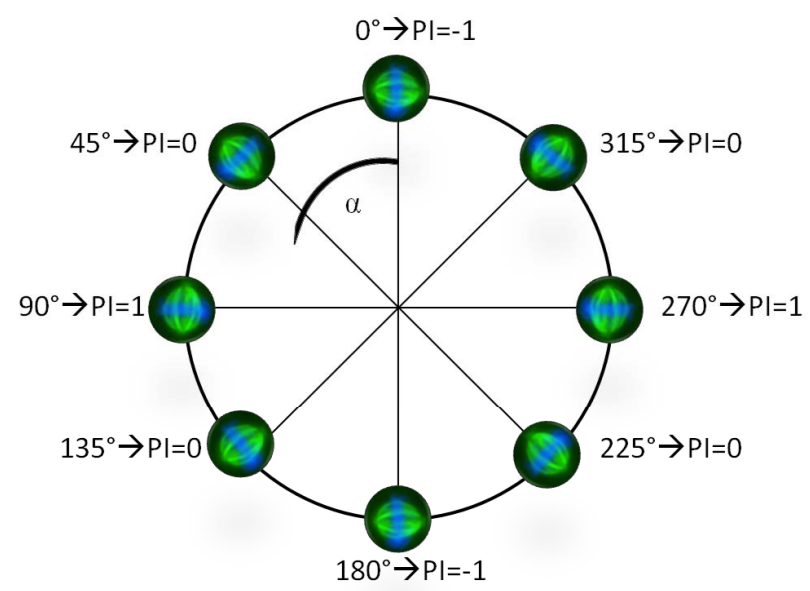

Fig. (4). Orientation of the cell cleavage plane.
Quantification of the orientation of the cell cleavage plane: With the help of the angles $\alpha$ (as determined above), the PI, which was introduced by Erickson [14], was calculated for every stimulation regime and every well. The polarization index quantifies the overall alignment of a number of cell divisions and was used for the comparison of data sets containing $\mathrm{n}$ angles $\alpha$. The PI was determined using the following equation:

$$
\mathrm{PI}=\frac{\sum_{i=1}^{n} \cos \left(2\left(\alpha-90^{\circ}\right)\right)}{n} .
$$

The PI can vary between -1 and 1. Fig. (4) shows exemplarily measured angles with their corresponding PIs determined with the equation above. A polarization index of -1 indicates a parallel orientation of the cell cleavage plane to the electric field vector. If the PI is determined to be 1 , the cell cleavage planes are orientated perpendicular to the electric field vector. A PI of 0 implies that the cell cleavage planes are distributed randomly and orientation did not occur.

Conventional statistic methods on linear data present difficulties when the values are distributions of circular frequencies. To verify the significance of these results, the correlating p-values were calculated:

$$
\frac{-\left(\left(\sum_{\mathrm{i}=1}^{\mathrm{n}} \cos 2 \alpha\right)^{2}+\left(\sum_{\mathrm{i}=1}^{\mathrm{n}} \sin 2 \alpha\right)^{2}\right)}{\mathrm{n}} .
$$

When dealing with data sets of angles, the p-value is used to test the significance of the difference between an orientation distribution and randomness. For example, a p-value of 0.1 indicates a probability of $10 \%$ that the obtained distribution of values is random. If $p$ is below 0.05 , the difference between the orientation distribution and a random distribution can be judged as statistically significant. [15] Only data sets with a probability less than $5 \%$ that the orientation distribution is random were used for evaluation. During the studies it was observed that the degree of orientation drops along the length of the electrode, the p-value rises with these decreasing PIs. It turned that the resistance increased with the length of the electrode. In the experimental set-up (Fig. 1A) one electrode covers the area of a row with 4 wells. That is why the electric field is higher in the first wells of one row, and the effect of the electrical stimulation decreased along the length of the electrode. Due to this finding, the data of the 1st to 3rd well of one electrode, which correlated with higher PIs and lower p-values, were chosen for the evaluation. The cells in the last well mostly did not exhibit any orientation.

Cell culture stimulation characteristics: A FEM simulation with COMSOL Multiphysics was conducted in order to assess the electric field strength. The real current was determined to be $2.3 \mathrm{~mA}$ per well, deploying a series resistor and an oscilloscope. The conductivity of the cell culture medium $(18.55 \mathrm{mS} / \mathrm{cm})$ and the permittivity of water $(80)$ 
were put as material properties in the finite element method model. Integration of the modeled current density over a plane between the electrodes with a sweep of voltages results in total currents that are matched with the measured current. The model with the matching total current gives us the electric field distribution in our experiment.

\section{RESULTS}

Evaluation of the electrodes, scanning electron microscopy (SEM): Before and after use, the electrodes were investigated using scanning electron microscopy.

The surface of the used electrodes was similar to that of the unutilized electrodes (Figs. 5A and $\mathbf{B}$ ) and no evidence of fouling, corrosion or other damage of the electrode material was detected.

Evaluation of the electrodes, energy dispersive $X$-ray (EDX): The electrodes were analyzed by dispersive X-ray during the SEM-session. The obtained spectral data file did not show any evidence of corrosion as can be seen in Figs. $(\mathbf{6 A}, \mathbf{B}$, and $\mathbf{C})$. The gold layer and the titanium layer under the covering platinum layer were detected, and some impurities were found, for example silicon (Si). Peaks of carbon $(\mathrm{C})$ and oxygen $(\mathrm{O})$ in Figs. (6A and $6 \mathrm{~B}$ ) indicate organic contamination of the platinum electrode surface.

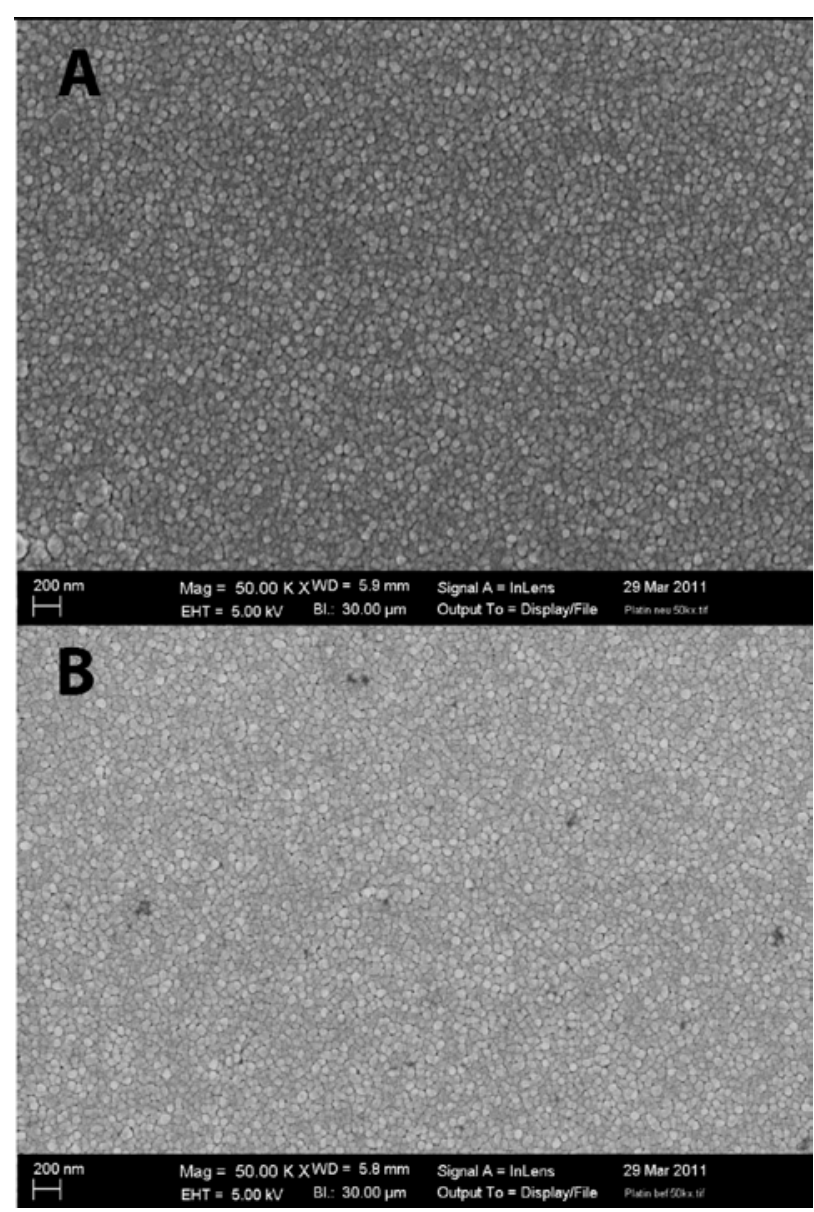

Fig. (5). A: Platinum electrode before use, B: Platinum electrode after cell culture stimulation.
In the EDX spectral data file (Fig. 6C) of PEDOT-coated electrodes, higher peaks of $\mathrm{C}$ and $\mathrm{O}$ were observed, resulting from the poly(3,4-ethylene-dioxythiophene)-layer.

Evaluation of cell culture stimulation: A FEM simulation was conducted in order to estimate the electric field strength using COMSOL Multiphysics. A voltage of $140 \mathrm{mV}$ was found to result in the measured total current. The corre-
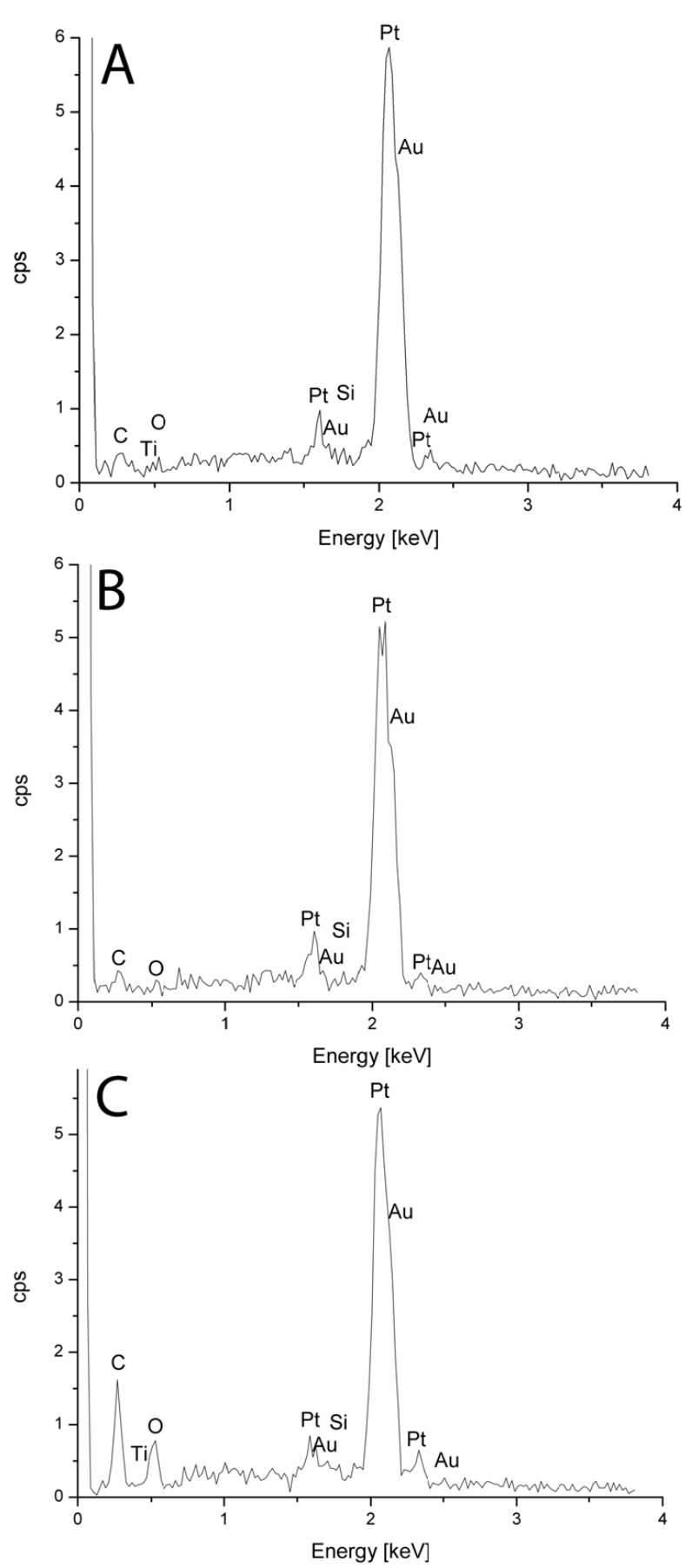

Fig. (6). A: EDX of a platinum electrode before use; B: EDX of a platinum electrode after use in cell culture and electrical stimulation; C: EDX-spectrum of a Pt-PEDOT-electrode. 


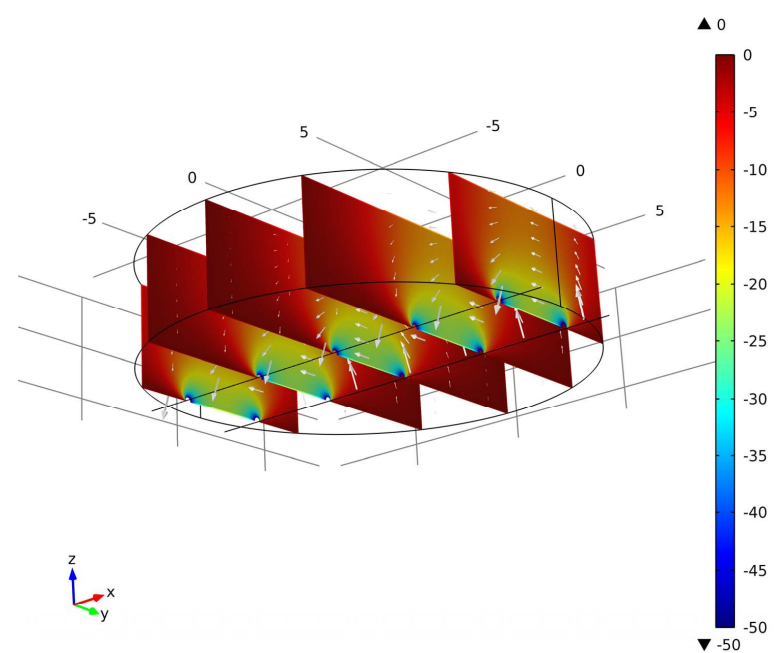

Fig. (7). Resulting electric field in V/m (colored slices) and current density (white arrows) during stimulating with $140 \mathrm{mV}$.

spondent electric field is depicted in Fig. (7).

The simulated field strength was $25-35 \mathrm{~V} / \mathrm{m}$ at $10 \mu \mathrm{m}$ height over well ground.

Orientation of cell bodies: In the following Fig. (8) the angles of orientation of the cell bodies are plotted. The angles have been subsumed in groups of $20^{\circ}$.

Figs. (8A and $\mathbf{8 B}$ ) show a vertical orientation of the cell bodies to the electric field vector. Both electrode materials, gold and platinum, were suitable for this stimulation experiment. Fig. (8C), which depicts the negative control, does not show a vertical orientation of the cell bodies.

Quantification of cell cleavage plane orientation: Fig. (9) depicts averaged PIs after stimulation with unipolar pulsed voltage, direct voltage, pulse-to-pause variations, control (no stimulation) and the naturally occurring PI of a wound in rat cornea in vivo as a comparative measure [4].

\section{DISCUSSION AND CONCLUSION}

We have successfully integrated an electrical stimulation device in a bioreactor for adherent cell culture. The SEM images and EDX spectra prove that the electrodes are stable under cell culture conditions and during electrical stimulation since no alteration in the elemental composition after use was detected in the spectra. Impurities were detected on new and utilized electrodes. Therefore it can be concluded that the impurities were not the result of corrosion, precipitation or degradation. New electrodes should be designed due to the finding that the electric field decreases along the length of the electrode.

Methods for the evaluation of electrical stimulation effects were established.

The obtained values of the polarization index were found in the same range as the in vivo polarization index occurring in wounds. The PIs after stimulation with direct voltage (without stimulation rest periods) were found to be in the same range as PI-values of stimulation with a 1:10-ratio of

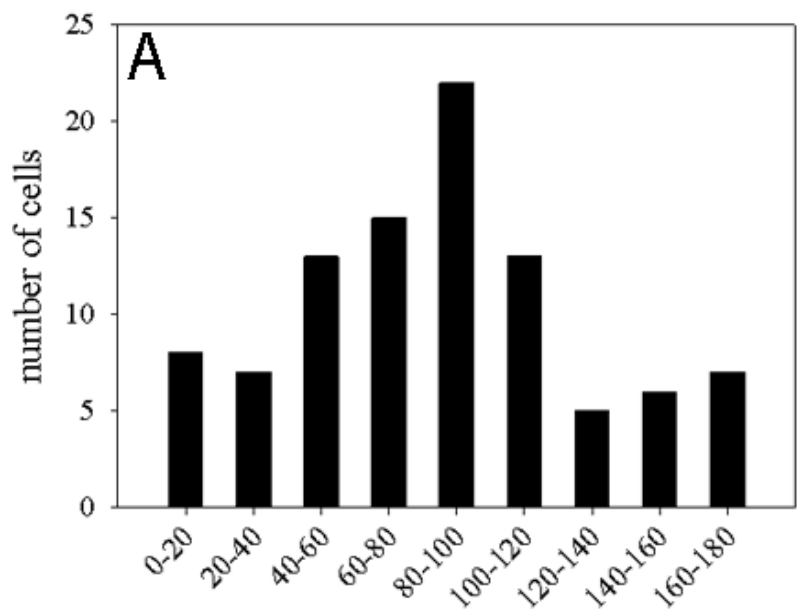

range of angles

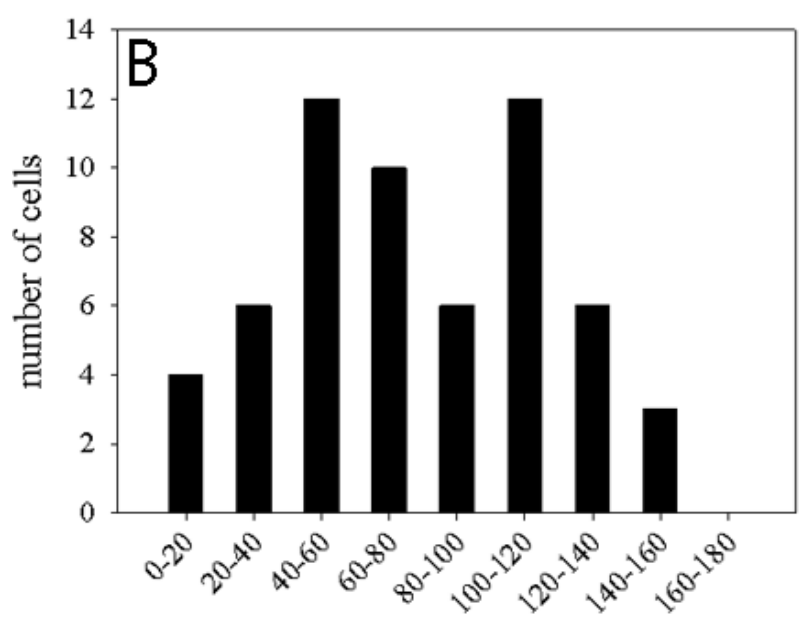

range of angles

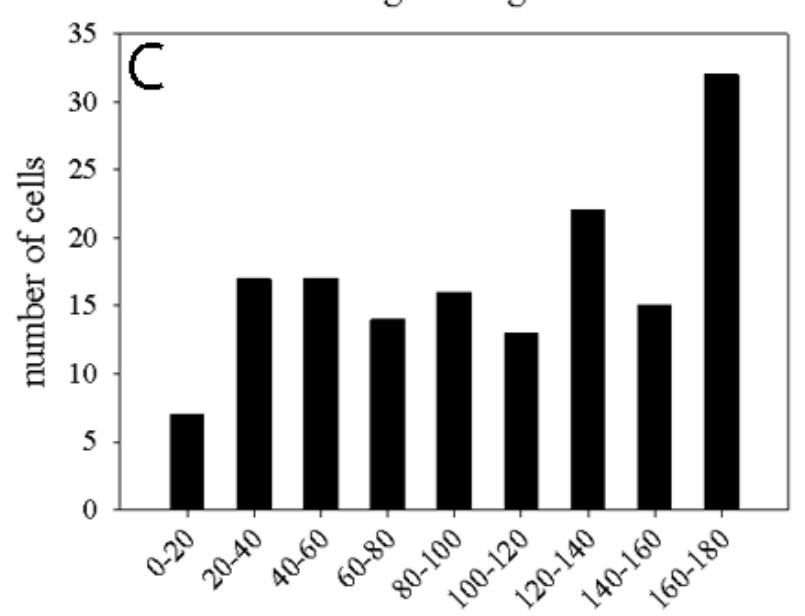

range of angles

Fig. (8). Orientation of cell bodies: A: Unipolar stimulation, gold electrode; B: Unipolar stimulation, platinum electrode; C: Control; non stimulated cells, gold electrode. 


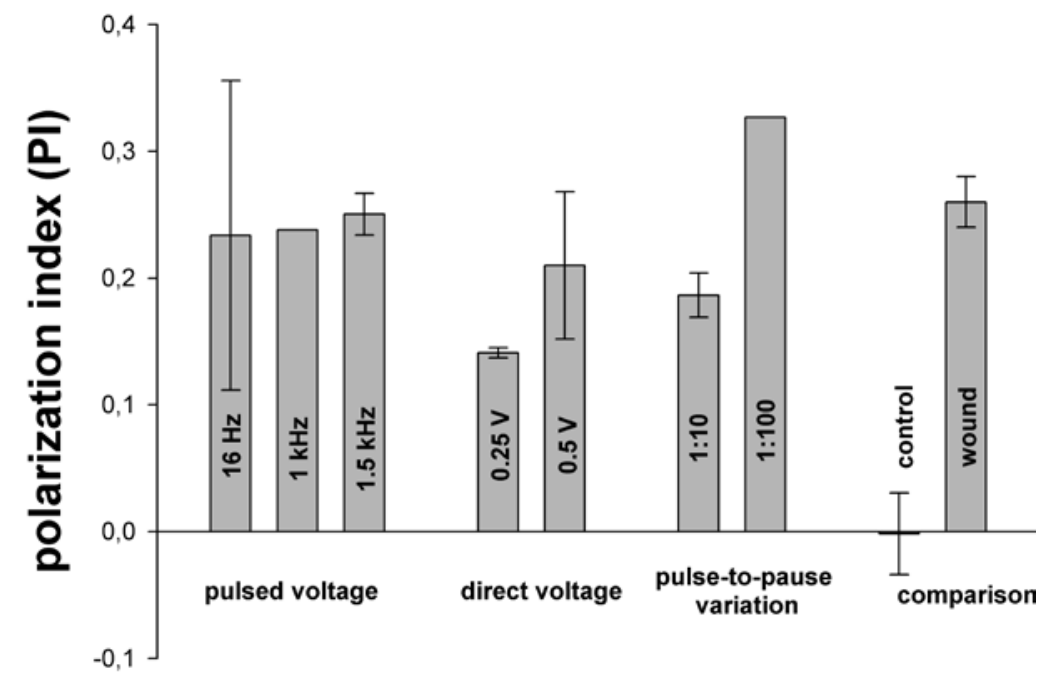

Fig. (9). Polarization indices of different stimulation regimes.

stimulation to pause. Even during pulsed stimulation with long rest periods, we could achieve high PIs. So it can be concluded that the energy input during stimulation with rest periods was sufficient. This stimulation regime offers the advantage of ion reflow, thus lessening the intensity of the electrical double layer on the electrode surface and the inhomogeneous distribution of ions in the cell culture chamber occurring due to their motion towards the electrode with opposite charge.

The ability of different stimulation regimes to influence the orientation of the cell cleavage planes was demonstrated. We achieved PIs that are known to be the result of the physiological electric field after wounding. We could not identify a frequency range, respectively pulse duration where the stimulation was more effective.

\section{CONFLICT OF INTERESTS}

None declared.

\section{ACKNOWLEDGEMENTS}

The authors gratefully acknowledge the support of the Bundesministerium für Bildung und Forschung (BMBF), grants number: $01 \mathrm{EZ} 0846$.

\section{ACRONYMS (ALPHABETICAL)}

$\begin{array}{lll}\text { CIC } & = & \text { Charge injection capacity } \\ \text { CPs } & = & \text { Counts per second } \\ \text { DAPI } & = & 4 \text { ',6-diamidino-2-phenylindole } \\ \text { DMEM } & = & \begin{array}{l}\text { Dulbecco's Modified Eagle's Me- } \\ \text { dium }\end{array} \\ \text { DNA } & = & \text { Deoxyribonucleic acid } \\ \text { EDOT } & = & \text { 3,4-ethylenedioxylthiophene } \\ \text { EDX } & = & \text { Energy dispersive X-ray } \\ \text { FITC } & = & \text { Fluorescein isothiocyanate } \\ \text { ICP } & = & \text { Inherently conductive polymer }\end{array}$

$\begin{array}{lll}\text { MTOC } & = & \text { Microtubule-organizing center } \\ \text { NIH-3T3 } & = & \text { Murine fibroblast cell line } \\ \text { PBS } & = & \text { Phosphate buffered saline } \\ \text { PEDOT } & = & \text { Poly(3,4-ethylenedioxythiophene) } \\ \text { PET } & = & \text { Poly(ethylene terephthalate }) \\ \text { PI } & = & \text { Polarization index } \\ \text { SEM } & = & \text { Scanning electron microscopy }\end{array}$

\section{REFERENCES}

[1] C. D McCaig, A. M. Rajnicek, B. Song and M. Zhao, "Controlling Cell Behavior Electrically: Current Views and Future Potential," Physiological Reviews, vol. 85, no. 3, pp. 943-978, 2005.

[2] B. Reid, B. Song, C. D. McCaig and M. Zhao, "Wound healing in rat cornea: the role of electric currents.” The FASEB Journal,vol. 19, no. 3, pp. 379-386, 2005.

[3] M. Zhao, B. Song, J. Pu, T. Wada, B. Reid, G. Tai, F. Wang, A. Guo, P. Walczysko, Y. Gu, T. Sasaki, A. Suzuki, J. V. Forrester, H. R. Bourne, P. N. Devreotes, C. D. McCaig and J. M.Penninger "Electrical signals control wound healing through phosphatidylinositol-3-OH kinase- $\gamma$ and PTEN," Nature, vol. 442, no. 7101, pp. 457-460, 2006.

[4] B. Song, M. Zhao, J. V. Forrester and C. D. McCaig, "Electrical cues regulate the orientation and frequency of cell division and the rate of wound healing in vivo," Proceedings of the National Academy of Sciences, vol. 99, no. 21, pp. 13577-13582, 2002.

[5] M. Zhao, J. V. Forrester and C. D. McCaig, "A small physiological electric field orients cell division," Proceedings of the National Academy of Sciences, vol. 96, no. 9, pp. 4942-4946, 1999.

[6] H. Seitz, S. Marlovits, I. Schwendenwein, E. Müller and V. Vécsei, "Biocompatibility of polyethylene terephthalate (Trevira ${ }^{\circledR}$ hochfest) augmentation device in repair of the anterior cruciate ligament,” Biomaterials, vol. 19, no. 1-3, pp. 189-196, 1998.

[7] Y. Li, T. Ma, S. Yang and D. A. Kniss, "Thermal compression and characterization of three-dimensional nonwoven PET matrices as tissue engineering scaffolds,” Biomaterials, vol. 22, no. 6, pp. 609618, 2001.

[8] W. Poppendieck, Untersuchungen zum Einsatz neuer Elektrodenmaterialien und deren Evaluation als Reiz- und Ableitelektrode. Dissertation. Engineering and Mechanical Engineering, Universitatdes Saarlandes, 2009.

[9] E. Hering, K. Bressler and J. Gutekunst, "Elektronik für Ingenieure und Naturwissenschaftler”, Mit 119 Tabellen. Springer, Berlin; Heidelberg; New York: XIX, 675 S, 2005.

[10] R. Starbird, W. H. Krautschneider, G. Blume and W. Bauhofer, "In Vitro Biocompatibility study and electrical properties of the 
PEDOT,” PEDOT collagen-coat, PEDOT nanotubes and PEDOT aerogels for neural electrodes. Biomedical Engineering (BioMed 2013). (Innsbruck, Austria: IASTED, 2013.).

[11] R. M. Miriani, M. R. Abidian and D. R.Kipke "Cytotoxic analysis of the conducting polymer PEDOT using myocytes. Engineering in Medicine and Biology Society,” EMBC 2008. In: 30th Annual International Conference of the IEEE: pp.1841-1844, 2008.

[12] S. Nagel-Heyer, C. Goepfert, F. Feyerabend, J. P. Petersen, P. Adamietz, N. M. Meenen and R. Pörtner, "Bioreactor cultivation of three-dimensional cartilage-carrier-constructs,” Bioprocess and Biosystems Engineering, vol. 27, no. 4, pp. 273-280 , 2005.

[13] DSMZ. 2011. Available from: http://www.dsmz.de/human_and_animal_cell_lines/cell_line_index.php [Accessed 7 May 2011].

[14] C. A. Erickson and R. Nuccitelli, "Embryonic fibroblast motility and orientation can be influenced by physiological electric fields," The Journal of Cell Biology, vol. 98, no. 1, pp. 296-307, 1984.

[15] J. R. Curray, "The Analysis of two-dimensional Orientation Data," The Journal of Geology, vol. 64, no. 2, pp. 117-131, 1956.

(C) Blume et al.; Licensee Bentham Open.

This is an open access article licensed under the terms of the Creative Commons Attribution Non-Commercial License (http://creativecommons.org/licenses/by-nc/3.0/) which permits unrestricted, non-commercial use, distribution and reproduction in any medium, provided the work is properly cited. 